\title{
Blockchain Research Agenda for Accounting
}

\author{
Nishani Edirisinghe Vincent ${ }^{1}$ \\ ${ }^{1}$ Assistant Professor of Accounting, The University of Tennessee at Chattanooga, 615 McCallie Avenue, \\ Chattanooga, TN 37403, USA \\ Correspondence: Nishani Edirisinghe Vincent, Assistant Professor of Accounting, The University of Tennessee at \\ Chattanooga, 615 McCallie Avenue, Chattanooga, TN 37403, USA. E-mail: surani-vincent@utc.edu
}

Received: September 9, 2019

Accepted: September 24, 2019 Online Published: September 25, 2019

doi:10.5430/afr.v8n4p93

URL: https://doi.org/10.5430/afr.v8n4p93

\begin{abstract}
Blockchain technology is causing a commotion in the business environment. Senior executives and board of directors are continuing to monitor and, in some cases, invest in blockchain with the hope of gaining a competitive advantage. However, the technology itself is still in the development stage. Even though there are many use cases presented for blockchain, the technology has to mature in order for firms and the business ecosystem to reap the benefits of the technology. Although traditionally the accounting profession has reaped the benefits of technological advancements, the profession has taken a more reactive approach to technology adoption. The purpose of this paper is to encourage the accounting profession to take a proactive approach and influence the development of blockchain by engaging in research related to blockchain technology. Therefore, in this paper, I provide a list of broad research questions related to blockchain based on major research areas in accounting. Given the broad range of questions presented here, accounting researchers can significantly influence the development and adoption of blockchain if researchers are willing to extend current research to a blockchain context.
\end{abstract}

Keywords: blockchain, research agenda, accounting

\section{Introduction}

Blockchain technology, initially known as the underlying technology of Bitcoin, has gained the attention of many professional organizations. According to a Gartner survey (2018), insurance and financial services, transportation, government, and utility sectors are at the forefront of blockchain planning and experimentation. These sectors anticipate significant process efficiencies and supply chain/logistic opportunities for using blockchain technology. The same survey indicates that 43 percent of CIOs are watching the development of the technology even though they do not have any action plans, 14 percent of CIOs have included blockchain in the medium or long-term plan, eight percent are actively planning for the technology, and one percent of CIOs have already invested in and are deploying blockchain projects. Even though there is an increased hype about blockchain, the technology is not yet sufficient for mission-critical enterprise use because of the evolving nature of the technical capabilities of blockchain.

However, the accounting profession continues to monitor and show an interest in blockchain in the hopes of improving data accessibility and security. Given the distributed nature of the technology, the accounting profession should anticipate many new challenges with regard to the blockchain technology. In May 2018, the American Institute of CPAs (AICPA) and its technology subsidiary came together with the Wall Street Blockchain Alliance (WSBA), a non-profit trade association created to guide, influence, and promote comprehensive adoption of blockchain technology across global markets, to discuss the strategy and direction of the advancement of blockchain technology. At the symposium, Susan Coffey, the executive vice president for public practice for the Association of International Certified Professional Accountants, said: "We [accounting profession] expect blockchain will impact all areas of practice".

Even though accounting has benefited from technological advancements in the past, the proliferation of technology in business has also introduced many challenges to the accounting profession. Throughout history, the accounting profession has taken a reactive approach to address these challenges imposed by technology. The recent update to the COSO integrated framework to reflect the increased use of technology and the emphasis on general information systems and application controls over financial reporting are just two examples of the reactive approach. However, given that the blockchain technology is still evolving, the accounting profession can take a more proactive approach and influence the development of technical capabilities, adoption, and implementation of blockchain solutions across 
supply chains, industries, and governments. More than other systems, the level of automation using smart contracts, collaboration spanning firms, industries, and/or governments, and the distributed nature of the blockchain ledger introduce new challenges to every area of accounting. If accounting researchers take a reactive approach to the development of blockchain, the accounting profession may not be able to reap the benefits of the technology. One reason for the lack of adequate research in accounting may be that, given the novelty of the technology, researchers are unaware of how they can bring their expertise to influence the development of blockchain. Consequently, in this paper, I discuss several areas that require accounting expertise at the crucial stage of development of the technology, so that the advancement of blockchain technology will embrace good corporate governance, enhanced security and privacy, adequate controls, operational efficiency, reasonable assurance, and fraud detection/reduction. In order to explain how accounting research can easily and naturally be extended to the blockchain context, the research questions are discussed within the dominant research areas of accounting.

The subsequent sections of this paper are organized as follows. Section 2 provides an introduction to the blockchain technology and briefly explores current accounting research in this area, section 3 introduces accounting challenges and research opportunities, and section 4 concludes the paper with some recommendations.

\section{Blockchain Technology and Current Research}

\subsection{Blockchain}

Simply stated, a blockchain is a digital record of transactions where the individual records are stored in blocks that are linked together in a single list called the chain. Even though the blockchain can be stored as a flat file or a simple database, the difference and the advantage resides in the blockchain data structure, which is ordered and linked to the previous block making it difficult to change a single transaction without affecting all the subsequent transactions. Hence, the two basic characteristics of a blockchain are decentralization and immutability. The use of the decentralized network eliminates the need for a central authority. The advantage of the peer-to-peer system is availability, i.e. even if one node in the network is unavailable, unlike a client-server architecture, the nodes can process and access information using the other available nodes on the network. Having a decentralized distributed network also eliminates a central authority and allows participants to verify and audit transactions, independently creating a consensus among the participants on what should be added to the blockchain. Immutability, the inability to change transactions entered into the blockchain, is a characteristic of the data structure which contains pointers to the previous block of transactions. Therefore, over time when more blocks are added to the blockchain, data tampering becomes extremely difficult. The basic components required to achieve immutability are further explained below.

A blockchain is made up of blocks which may include many transactions. Each block contains a block header containing metadata and transactions. Each block is identified by a block hash in the block header. Further, a block header also contains a reference to the previous block hash establishing a valid link to the blockchain. A block hash is computed by each node as the transactions are received from the network; therefore, even a simple change in the transactions included in a block will result in a different block hash. By including the cryptographically hashed previous block header in the metadata of the current block, the blocks are ordered into a continuous chain. As blocks become available to the network, each node will validate the blocks and link it to the existing chain by verifying the previous block hash in the block header. Even though block height, i.e. the position of the block in the blockchain, is not a unique identifier, it can also be used to identify blocks in a blockchain (Note 1).

Blockchains can be characterized into three different types: permissionless, permissioned, or hybrid form. For example, permissionless blockchain will allow any node to participate in validating transactions and adding blocks to the blockchain while a permissioned blockchain will only allow verified or previously known nodes to participate in the mining process. The hybrid form uses a mix of permissioned and permissionless features. There are advantages and disadvantages to both forms which will be briefly discussed in the research opportunities section.

\subsection{Current Research in Accounting}

Currently, the American Accounting Association (AAA) Journals retrieved three articles in Current Issues in Auditing, six articles in the Journal of Emerging Technologies and one article in the Journal of Information Systems. Kokina, Mancha, \& Pachamanova (2017) conduct a preliminary analysis of the technology and provides opportunities and limitations of the blockchain. Coyne and McMickle (2017) explore the use of blockchain as a financial reporting tool and conclude that it is infeasible to implement given that economic transactions exist outside of accounting records hence it prevents an acceptable level of transaction verification. Several papers explore the implications of blockchain to the auditing practice (Rozario and Thomas, 2019; Gomaa, Gomaa, \& Stampone, 2019; Dai, He, \& Yu, 2019; Liu, Wu, \& Xu, 2019). Further, Dai and Vasarhelyi (2017) provide a preliminary design for a 
real-time, verifiable, and transparent accounting ecosystem. Sheldon (2018) proposes a new use case for blockchain, i.e. an accountancy blockchain to aggregate and share instances of practitioner misconduct across the country on a real-time basis. Sheldon (2019) discusses the risks and information technology general controls to private and permissioned blockchains auditors need to be aware as part of the internal control over financial reporting. Tang and Tang (2019) show how to use the blockchain ledger to account for emissions trading and carbon management.

A search on The ProQuest database retrieves thousands of search items on blockchain. However, the majority of articles are related to the use of blockchain for cryptocurrencies. Karajovic, Kim, \& Laskowski (2019) provide a comprehensive discussion of various phases of blockchain integration in the accounting industry. They also discuss various issues that have risen as projects move through the development cycle. Schmitz and Leoni (2019) conduct an analysis of accounting literature and identify four key themes related to blockchain, namely, governance, transparency and trust, continuous audit, smart contracts and accountants' and auditors' roles. Based on their findings they recommend the accounting profession to broaden their skillset and knowledge in order to meet the demands of their clients and suggests that accountants and auditors can play a pivotal role in the generation, execution, and control of smart contracts. As part of the discussion, they provide three to four research questions related to the four themes identified above. Further, Carlin (2019) suggests blockchain development requires diverse perspective and that there is a lack of meaningful contributions from the accounting community to legitimize, shape, and influence blockchain development. The need for further research in blockchain as related to the accounting profession is apparent. However, the technical nature of the current questions such as how to handle hard forks, or what is the optimal mining algorithm, etc. makes the accounting community shy away from influencing the development process through research. Therefore, in this paper we further expand on the research areas, present research questions based on the specific area of expertise within accounting, and show how and why accounting research can/should influence the development of blockchain technology.

Further, a keyword search on the SSRN for early-stage research on blockchain in the accounting field revealed 24 articles. However, six out of the 24 articles were on cryptocurrencies and four articles were on crowdfunding, initial coin offering, investment fund regulation, and commercial law respectively. One article was published and is discussed above. Of the 14 remaining articles, four articles were related to tax issues such as payroll, VAT, and trade barriers and regulatory tariffs. Further, ongoing research explores the application of blockchain and implications to financial accounting (Chandra Shekar, Kumaran, \& Mishra, 2018; Yu, Lin, \& Tang, 2018) and auditing (Cao, Cong, \& Yang, 2018), the relevance of blockchain's open information concept (O'Leary 2018), literature reviews and comparisons (Breerbaum 2018; Tan 2018). Fenwick, MaCahery, and Vermeulen (2018) explore an emerging new business model which is a platform model and discusses the implications for regulation and corporate governance. Wang and Kogan (2017), the only design-related article, develops a prototype to demonstrate the functionality of a blockchain-based accounting system. Tan and Low (2019) discuss the design of blockchain and suggest that existing systems will connect to blockchain rather than replace the systems. However, they do not examine how this link will be established. Vincent, Skjellum, \& Medury (2019) expands on this notion and introduces the basics of the mechanisms of how to connect the existing system to the blockchain.

Consequently, given the limited research in the field of accounting, I offer broad research questions to create more opportunities for blockchain research in accounting that will be beneficial to the development of the correct capabilities in the technology. The next section discusses these research opportunities.

\section{Accounting Challenges and Research Opportunities}

For the purpose of this article, the research opportunities in accounting are broadly categorized into four distinct accounting research areas: accounting information systems, auditing, management accounting, and corporate governance/financial reporting/capital markets. Even though the research areas are not comprehensive, I believe these four broad accounting avenues can provide guidance on and have the greatest impact on the design of the technology, the architecture, and the capabilities of blockchain. The subsequent sections briefly discuss these research opportunities.

\subsection{Accounting Information Systems Related Research Opportunities}

Given the overlap of concepts with information systems, accounting information systems research can significantly impact the design, implementation, and operations of blockchain technology. One of the initial research areas that require accounting expertise is in designing the architecture of blockchain technology. Currently, there is confusion among professionals on how to leverage this technology. Even though blockchain developers and technology professionals recognize the benefits of the technology, there is a lack of direction on how to design the architecture to improve efficiency and effectiveness of supply chains or the whole business ecosystem. The solutions currently 
being presented mirror existing architectures with relational databases. Therefore, given the expertise in business transactions and information systems, AIS researchers could address questions such as: What is a viable blockchain architecture? Are there differences in operational efficiencies among various architectures? What are the anticipated/unanticipated costs of specific architectures? How can specific architectures be generalized to meet various industries, supply chains, and/or business ecosystems? What are the operational and assurance benefits of selecting a permissioned versus a permissionless blockchain? What are the drivers (strategy, operational, regulatory/reporting compliance, etc.) and benefits (transparency, access to information, assurance, etc.) of a specific architecture?

Once research addresses the architectural issues, AIS research could also explore: What information should be included in the blockchain? Why certain information should be included, the benefits of maintaining such information on the blockchain, and what information should be combined together (hashed together)? How often should blocks be added to the blockchain-based on competitive, strategic, operational, and compliance requirements?

Further, AIS research could also address questions related to the conceptual design of the technology. Traditionally, systems design starts by identifying system boundaries and these boundaries are generally well defined by the ownership of a specific firm. For example, designing an accounting application will consider a specific firm's accounting department as a system boundary. Further, system design considerations until now have reflected only on one entity. Even when we design supply chain integration, the design of interfaces considers the integration from the perspective of one entity. However, blockchain disrupts the traditional design approach by considering business ecosystems rather than one entity. First, research should address whether the business ecosystem is appropriate for a blockchain use case. Hence, question and explore the perceived benefits for the blockchain use case for the business ecosystem. Further, research should also provide guidance on how to define the system boundary for a blockchain project.

Given a business ecosystem, we will have to reflect on whether tools and techniques used to design information systems are adequate. AIS research can address issues such as: Can current entity-relationship (E-R) diagrams be used to adequately represent industries, supply chains, and/or business ecosystems? If not, how can we expand E-R diagrams to include many entities rather than a single entity approach to design? Given the popularity of Resources-Events-Agents (REA) diagrams in accounting, AIS research could address the above two questions about REA diagrams (Note 2). Further, AIS researchers could take a design science approach and identify whether there are new artifacts of design in a blockchain environment. If new artifacts are found, research should guide practice on how to design, adopt, and implement these artifacts. Further, research should explore whether new artifacts perform consistently in various contexts.

AIS research could also explore perceived implementation challenges, such as: Whether there are new implementation challenges given the involvement of multiple entities? What is the total cost of blockchain adoption? Should the cost be shared between the parties and how? What are project management challenges? Who should be part of the project team, the role, and skills of the project team, and who should lead the project team given the involvement of multiple entities? Are there new project risks associated with blockchain implementations? What are the risks associated with a blockchain implementation? What is the role of internal audit/accounting in blockchain implementations?

Adoption of blockchain will significantly impact enterprise risk management. Therefore, accounting researchers have the expertise to address issues and concerns related to governance and enterprise risk management. Research should explore and provide guidance on: Who should govern the blockchain? What is the best governance structure for blockchain given the multiple entity/party/stakeholder involvement? How do we incorporate blockchain risks in enterprise risk management? Can best practice models be developed to share the risk of blockchain among parties, and if so, what is the optimal solution? Do current frameworks such as COSO integrated, enterprise risk management, NIST, COBIT frameworks address all aspects of the blockchain environment? What are best practices in blockchain adoption? What factors affect blockchain adoption? Can the technology adoption model be applied in a blockchain environment, what factors are not considered?

\subsection{Auditing Related Research Opportunities}

Given the nature of the technology and the potential benefits for assurance, auditing researchers can significantly influence the development, advancement, and adoption of the blockchain. Auditors can and should get involved early in the development process and address issues on data accuracy, completeness, validity, and reliability. Auditing perspective can significantly influence the design of the blockchain; therefore, the auditor is a critical project team member that can help address issues discussed in the AIS research opportunities. Auditors could critically assess 
client's use cases for blockchain and address the relevance of the blockchain technology. Further, auditing research could focus on the impact of blockchain on audit risks. For example, research should explore: Will audit risk decrease as a result of blockchain technology? How will the audit risk decrease? What new risks are introduced? What is the impact of these new risks on the overall audit? What will be the impact of blockchain adoption and the associated risks on audit fees? What are the benefits and challenges to continuous auditing as a result of blockchain technology?

Further, auditing research could significantly influence the controls built into the blockchain environment. As mentioned in the AIS research opportunities section, when deciding on which data/information should be included in the blockchain, audit expertise could help in designing the appropriate preventive, detective and corrective controls. Auditors could also explore the possibility of executing various fraud scenarios and provide guidance on how to minimize fraud by built-in controls. For example, when a transaction is modified after the initial entry to the blockchain, auditing research could guide: What 'markers' help identify such modifications? What are the important changes that should be flagged? What is the best method to hash transactions, i.e. should transactions be hashed as a total or should a portion of the transaction be hashed to identify modifications?

Also, research in this area could influence security, privacy, and confidentiality issues that come up during the design of a particular blockchain. Another area of concern for the auditing profession is the changes to audit procedures. Research should explore: Whether audit assertions and audit procedures would change as a result of blockchain technology? What audit procedures should be built-in for continuous monitoring? Are there audit assertions that would be implied as a result of blockchain adoption? How do you provide assurance over the algorithms and smart contract codes? What are good practices of code structures that enable and assist an audit? What are the anticipated changes that impact audit work? How, and what new skills should be included as part of employee training?

CPA firms may also be interested in exploring the incentives that will encourage client firms to embrace the blockchain technology. Therefore, research in this space should explore: How to encourage clients to embrace the technology? Whether the adoption of blockchain would hinder the client's ability to change audit firms? How will client lock-in impact auditor independence? Addressing such questions at the early stages of development will not only provide guidance on development but also will help establish proper requirements for compliance and regulation.

Once the data is available on a blockchain, the auditing profession has to be able to access the data for a specific client. Currently, data on the blockchain is only displayed as hashes of the transactions. Therefore, there is a lot of opportunities in Decentralized Application (DApp) development. If the auditor wants to understand the data, he/she needs to be able to unhash the transactions. Therefore, auditing research should guide these developments and prescribe what information should be unhashed (retrieved) and how should the data be organized.

Given the novelty of the technology and the height of enthusiasm from the accounting profession about the potential benefits of the technology, auditing research should also consider the professions readiness to embrace the technology. Therefore, research should explore: Whether there is a need for skill development in the profession? What types of skills are required to guide a blockchain project? What is the role of the auditor in blockchain development and implementation? Can internal auditing be leveraged in blockchain development and how? What staffing challenges should be anticipated and how to address these challenges? Since most universities prepare the majority of accounting students for a public accounting career, research should also explore changes needed to the accounting curriculum in order to address the skills and competencies required by the public accounting industry.

\subsection{Management Accounting Related Research Opportunities}

The Institute of Management Accountants (IMA) defines a management accountant as "accounting and financial workforce that help drive an organization's strategy and value amid unpredictable market (www.imanet.org)." Thus, management accountants provide vital information to the management on strategic alignment of business operations, financial performance, state of company's assets, potential investment opportunities and the adequacy of funds, and business sustainability for the decision making process. Therefore, research in this area could guide management accountants to add value to the advancement of blockchain technology.

The initial area of management accounting research could focus on the investment of blockchain. Research should provide guidance or solutions to issues such as: What is the total cost of blockchain development? Is the adoption of blockchain feasible? What are the appropriate use cases of blockchain development? What is the economic impact of blockchain on business operations? What are the information needs of various business parties that could potentially 
benefit from blockchain adoption? Further, future research could identify the determinants of technical, operational, scheduling, and compliance feasibility of blockchain.

Another area of advancement with regard to blockchain technology is the development of smart contracts. Using blockchain as the underlying technology, smart contracts self-execute computer code based on a set of predefined rules under which contracting parties agree to interact with each other. One of the perceived benefits of smart-contracts is the reduction in transaction costs (Deloitte, 2016). However, there is a pressing need to understand the impact of smart contracts on transaction costs. Hence research in this area should provide adequate explanations as to: How does a smart contract reduce transaction costs? What are the costs of transacting using blockchain smart contracts? Who should pay the transaction cost of executing a smart contract and why? Should costs be shared, if so, how should it be shared? Can or should smart contract have the ability to transfer transaction costs among the contracting parties? Under which conditions should transactions costs be transferred? What is the impact of the transaction cost of a smart contract on the final product? Is it truly economical than the existing processes? Further, the execution of smart contracts, for example under the Ethereum blockchain, may depend on factors such as the cost of energy and the effort (gas). Since the amount of energy and effort required to execute a smart contract will depend on the efficiency of the code, management accounting research could influence the development of the blockchain protocol for smart contracts by exploring issues related to the efficiency of the code. Research could explore: What is the breakeven point of transaction costs based on specific code structures? How will the cost of energy, storage, execution, and effort (gas) impact transaction cost? What is the impact of estimate smart contract transaction costs on contract negotiations?

Further addressing the performance of blockchain can help the blockchain industry develop cost-efficient, operationally feasible, and secure solutions. For example: Is there an impact on the final price to the customer given blockchain adoption? How will blockchain adoption impact the vendor selection process? What is the impact of the transaction cost of a smart contract on the bottom line? What are the key performance measurements of blockchain? What should be a benchmark of smart contract performance? How should the performance of smart contract be assessed?

As we are in the development stage of the blockchain, the accounting profession has the ability to influence and enhance the functionality, operations, and maintenance of the technology. However, researchers should not only address issues related to the operation, functionality, and security but also should consider the impact of this technology on future generations. In recent years, sustainability has become a hot topic among regulators, and as a result, the board of directors and management. Blockchain technology creates a huge burden on the environment because it consumes an exorbitant amount of energy for the mining processes (Zhao, 2017). This leads to a series of questions such as; Are blockchain-based solutions sustainable? What is the long-term and short-term environmental impact on blockchain? How can we make blockchain sustainable? Do we need a form of compliance with regard to blockchain? What are the viable use cases of sustainability? What are the risks associated with the sustainability of blockchain? How do you measure the impact of environmental effect given the decentralized network? Who should be responsible for the sustainability of blockchain? What are the reporting requirements and performance measurements of blockchain and who should report it? What should be sustainability standards for the blockchain? How will blockchain sustainability impact customer/ investor perceptions?

\subsection{Corporate Governance and Financial Reporting Related Research Opportunities}

Another important area of accounting research related to blockchain technology is corporate governance. The importance of governance and the oversight role of the board of directors was reiterated after the introduction of the Sarbanes Oxley Act of 2002 and the enhanced proxy disclosures of 2010. Given the responsibility of the profession towards the public, accounting research could explore issues in the context of blockchain governance. Since financial reporting focuses on one single entity, blockchain and smart contract developments may impose some challenges to the existing requirements. For example, Will blockchain change the firm-specific financial reporting to supply chains/collisions/industries? Who should be responsible for the governance of blockchain? What is the role of the corporate board given most use cases involve supply chains, collisions, and/or industries? What aspects should be disclosed with regard to blockchain adoption? Should blockchain risk be a unique disclosure item in the risk factors? Who should be responsible for the disclosure requirements? Can regulators use blockchain for compliance, if so how? What aspects of firm information should be accessible to regulators? Will blockchain replace the need for XBRL reporting? 


\section{Conclusion}

The heightened interest in the blockchain technology in the accounting profession calls for proper guidance into the adoption, implementation, and use of the technology. Even though the underlying technologies of blockchain, such as the decentralized network and cryptography, is not novel, the combined use and the introduction of a common distributed ledger introduces some interesting uses of the technology. Additionally, the technology continues to develop and address issues of security, efficiency, and capability. However, continuous development is scarcely driven by research. Therefore, there is an opportunity for researchers to get involved in the early stage to provide guidance and direction for technology development and adoption. Since the technology is still developing, most accounting researchers hesitate to delve into research in this area. Even AIS researchers mostly deal with the adoption, implementation, use, control of a well-developed product. Therefore, blockchain technology poses a challenge to the accounting researcher. However, this unique situation opens a door to influence the development of technology from an accounting perspective. Given the expertise in data collecting, organizing, analyzing, reporting and interpreting, accounting research has an opportunity to direct the development of the technology. However, there is one big challenge that we need to overcome if we are to address the above issues and make an impact on the development process. That is, as accounting researchers we cannot work in our own silos. We have to engage in diverse research teams. We need to collaborate with colleagues in computer science and engineering. We also need to collaborate with marketing, information systems, management, finance, and economics if we are to dive further into the board areas discussed above and contribute to extending knowledge and directing the profession.

Finally, readers should note that the research topics discussed above are not an exhaustive list of research opportunities. As researchers dive into blockchain research other opportunities may arise. Further, as the firms move from an experimental stage to having operational systems accounting research could further enhance the use of the technology by developing new use cases, establishing new connections, and designing new performance measures for control.

\section{References}

American Institute of Certified Public Accountants (AICPA). (2018). Accounting firm leaders and innovators gather for strategic discussions on blockchain technology. Retrieved from https://www.aicpa.org/press/pressreleases/2018/firm-leaders-innovators-gather-for-discussions-on blockchain.html.

Beerbaum, D. (2018). Blockchain-A Business Case for XBRL: A Beast or a Lame Duck? Available at: https://ssrn.com/abstract=3174431. http://dx.doi.org/10.2139/ssrn.3174431

Cao, S., Cong, L. W. \& Yang, B. (2018). Auditing and blockchains: Pricing, misstatements, and regulation. Available at: https://ssrn.com/abstract=3248002. http://dx.doi.org/10.2139/ssrn.3248002

Carlin, T. (2019). Blockchain and the journey beyond double entry. Australian Accounting Review, 29(2), 305-311.

Chandra Shekar, M., Kumaran, R. \& Mishra, R. K. (2018). Blockchain technology - An exploratory study on its applications. The Management Accountant, June 2018. Available at: https://ssrn.com/abstract=3194522.

Coyne, J. \& McMickle, P. (2017). Can blockchains serve an accounting purpose? Journal of Emerging Technologies in Accounting, 14(2), 101-111. https://doi.org/10.2308/jeta-51910

Dai, J. \& Vasarhelyi, M. A. (2017). Toward blockchain-based accounting and assurance. Journal of Information Systems, 31(3), 5-21. https://doi.org/10.2308/isys-51804

Dai, J., He, N. \& Yu, H. (2019). Utilizing blockchain and smart contracts to enable audit 4.0: From the perspective of accountability audit of air pollution control in China. Journal of Emerging Technologies in Accounting In-Press. https://doi.org/10.2308/jeta-52482

Deloitte. (2016). Blockchain technology- the benefits of smart contracts. Retrieved from https://www2.deloitte.com/nl/nl/pages/financial-services/articles/blockchain-technology-the-benefits-of-smart-c ontracts.html.

Fenwick, M., McCahery, J. A. \& Vermeulen, E.P. (2018). The end of 'corporate' governance: Hello 'platform' governance. Available at: https://ssrn.com/abstract=3232663. http://dx.doi.org/10.2139/ssrn.3232663

Gartner. (2018). Gartner survey reveals the scarcity of current blockchain deployments. Press release on May 3, 2018. Retrieved from https://www.gartner.com/newsroom/id/3873790. 
Gomaa, A., Gomaa, M. \& Stampone, A. (2019). A Transaction on the blockchain: An AIS perspective, intro case to explain transactions on the ERP and the role of the internal and external auditor. Journal of Emerging Technologies in Accounting In-Press. https://doi.org/10.2308/jeta-52412

Kokina, J., Mancha, R. \& Pachamanova, D. (2017). Blockchain: Emergent industry adoption and implications for accounting. Journal of Emerging Technologies in Accounting, 14(2), 91-100. https://doi.org/10.2308/jeta-51911

Karajovic, M., Kim, H. M. \& Laskowski, M. (2019). Thinking outside the block: Projected phases of blockchain integration in the accounting industry. Australian Accounting Review, 29(2), 319-330. https://doi.org/10.1111/auar.12280

Liu, M., Wu, K. \& Xu, J. (2019). How will blockchain technology impact auditing and accounting: Permissionless vs. permissioned blockchain. Current Issues in Auditing In-Press. https://doi.org/10.2308/ciia-52540

O'Leary, D. (2018). Open information enterprise transactions: Business intelligence and wash and spoof transactions in blockchain and social commerce. Available at: https://ssrn.com/abstract=3246740. http://dx.doi.org/10.2139/ssrn.3246740

Rozario, A. \& Thomas, C. (2019). Reengineering the Audit with Blockchain and Smart Contracts. Journal of Emerging Technologies in Accounting In-Press. https://doi.org/10.2308/jeta-52432

Schmitz, J. \& Leoni, G. (2019). Accounting and auditing at the time of blockchain technology: A research agenda. Australian Accounting Review, 29(2), 331-342. https://doi.org/10.1111/auar.12286

Securities Exchange Commission. (2010). Proxy disclosure enhancements. 17 CFR PARTS 229, 239, 240, 249 and 274 [Release Nos. 33-9089; 34-61175; IC-29092; File No. S7-13-09]. Retrieved from https://www.sec.gov/rules/final/2009/33-9089.pdf.

Sheldon, M. (2018). Using blockchain to aggregate and share misconduct issues across the accounting profession. Current Issues in Auditing, 12(2), A27-A35. https://doi.org/10.2308/ciia-52184

Sheldon, M. (2019). A primer for information technology general control considerations on a private and permissioned blockchain audit. Current Issues in Auditing In-Press. https://doi.org/10.2308/ciia-52356

Tan, B. (2017). Blockchain-A database with a twist. Available at: https://ssrn.com/abstract=2958565. http://dx.doi.org/10.2139/ssrn.2958565

Tan, B. S. \& Low, K. (2019). Blockchain as the database engine in the accounting system. Australian Accounting Review, 29(2), 312-318. https://doi.org/10.1111/auar.12278

Tang, L. \& Tang, Q. (2019). Towards a distributed carbon ledger for the integration of carbon asset management and emissions trading. Journal of Emerging Technologies in Accounting In-Press. https://doi.org/10.2308/jeta-52409

Vincent, N. E., Skjellum, A. \& Medury, S. (2019). Blockchain architecture: A design that helps CPA firms leverage the technology. Working paper.

Wang, Y. \& Kogan, A. (2017). Designing privacy-preserving blockchain based accounting information systems. Available at SSRN: https://ssrn.com/abstract=2978281. http://dx.doi.org/10.2139/ssrn.2978281

Yu, T., Lin, Z. \& Tang, Q. (2018). Blockchain: Introduction and application in financial accounting. Available at: https://ssrn.com/abstract=3258504. http://dx.doi.org/10.2139/ssrn.3258504

Zhao, H. (2017). Bitcoin and blockchain consume an exorbitant amount of energy. These engineers are trying to change that. CNBC. $\quad$ Retrieved from https://www.cnbc.com/2018/02/23/bitcoin-blockchain-consumes-a-lot-of-energy-engineers-changing-that.html.

\section{Notes}

Note 1. A block contains many transactions. Consequently, a block is analogous to a batch. Even though batches could be uniquely identified with batch numbers hence sorted, it lack the immutability characteristic of blocks.

Note 2. E-R and REA diagrams are documentation techniques (pictures) used to conceptually design an information system or to understand the functioning of an existing system. They are analogous to the blue prints an architect provides regarding a building design. E-R and REA diagrams use specific symbols to represent various aspects of the process, system, and/or system components, making it efficient to document and easy to understand. 